\title{
Teaching Technology As Assisted Language Learning (TALL) Subject: How Does It Work?
}

\author{
Ildi Kurniawan \\ Engish Education Department \\ Bengkulu University \\ Bengkulu, Indonesia \\ ildikurniawan@unib.ac.id
}

\author{
Syafrizal Sabaruddin \\ English Education Department \\ Bengkulu University \\ Bengkulu, Indonesia \\ Syafrizal_sabaruddin@yahoo.com
}

\begin{abstract}
Technology as Assisted Language Learning (TALL) subject with code ING-349 is a subject with 2 credits at the English Department of Bengkulu University and the subject is offered to students at the fifth semester. This compulsory subject is designed to help students with some applicable technologies which are important for students as a learner and a future teacher. This subject provides students with current technologies which can be used for their English teaching and learning in the future. This paper is aimed at discussing about Teaching TALL subject at the English Department of Bengkulu University which covers about teaching materials, teaching procedures or methods, tasks or assignment, and evaluation system and feedback.
\end{abstract}

Keywords—teaching, technology, language, learning

\section{INTRODUCTION}

Technology plays an important role in education field specifically for teachers and students in improving their teaching and learning experience [1]. Unfortunately, the use of technology itslef in education is still low because just few teachers use it especially in develpoing countries [2]. On the other hand, in the future, the teachers are expected to prepare themselves to teach their students more interactive and align with the demand of the twenty-first century education.

The use of technology in language teaching and learning has been conducted by some educators recently. One of the example is mobile technology $[3,4,5,6]$. Other examples are web-blog (Lina, 2017) social media (Haylett, 2016), videos such you tube or skype (Morris and Tsakissiris, 2017); flipped classroom (Lo and Hew, 2017).

Dealing with the benefits of technolgy, some experts state that the technology gives significant impact on student's language learning proficiency, engagement, and other learning outcomes [7, 8, 9]. Furthermore, technology can be an important tool to get knowledge and share information and it can boost new directives for teachers and stimulate the learner's mind [10]. However, the problems faced by teachers concerning about the technology are lack of training and lack of background knowledge of the technology as well (Jones, 2016) so that they do not have any ideas on how to use the technology in teaching and learning process [11].
Therefore, apart from other articles, this article tries to give solution for teachers to teach technology which is useful for students in their language learning and teaching. In this article complete steps on teaching TALL subject are discussed and then it will be ended with reflection, recommendation and conclusion about teaching TALL subject.

\section{STEPS FOR TEACHING TALL}

\section{Step 1. Preparation \\ 1) Preparing Syllabus}

Syllbus is a plan showing the subjects or books to be studied in a particular course, especially a course which leads to an examination. Therefore, syllabus becomes crucial for teacher and student to have. In TALL subject, the syllabus should give all information needed by students so that they know what to learn and to do next meeting. At least, in the syllabus they can get information about the indentity of the subject, the goals of the subject, the skill they will get, and materials that should be read, and other rules: present, class particiption, the assignment/project, grading system and so forth.

\section{2) Preparing Learning Materials and Tools}

The materials which are going to be used in TALL subject should consider the three things below:

a) Affordable and or free /downloadable materials: There are many materials available on internet but perhaps because of financial problems, the teacher can choose free materials. What the teacher should do is try to google what suitable and best materials for their children to have. Make a list and get students to download them.

b) Simple but applicable materials: It is highly recommended to use easy and useful materials for students because not all students have high skill in using technology. In addition, since they are as future teacher and students make sure the materials are applicable for student's need.

c) Online or offline access: Some applications are designed for online and offline mode or setting. Therefore, to ensure this type of access, the teacher should check it before use it. If it is online, internet connection is needed, and vice versa. 
Considering the three things above, here are the examples of learning materials for students in teaching TALL subject. The topics are categorized into some groups based on their similarities in function in technology.

TABLE I. LEARNING MATERIALS

\begin{tabular}{|l|l|}
\hline Types of Technology & Example of application \\
\hline Browsers & $\begin{array}{l}\text { Google image, Google scholars, Google } \\
\text { voice }\end{array}$ \\
\hline Presentation tools & Prezi, Power point \\
\hline Video & Youtube, Ted.com \\
\hline Video Editor & Windows Movie Maker \\
\hline Audio & Podcast, British Council, VOA, Podmatic \\
\hline Audio Editor & Audacity \\
\hline Burner & Nero \\
\hline Image & Paint, microsoft office, picture manager \\
\hline Comics & paint \\
\hline Screen Capture & Laptop, camera, handphone \\
\hline Converter & Nitro Pro 9, Nuance Pdf \\
\hline $\begin{array}{l}\text { Online Storage \& } \\
\text { Sharing }\end{array}$ & dropbox, 4share \\
\hline Survey tools & Survey monkey, google forms \\
\hline
\end{tabular}

On the other hand, the tools which are used in teaching TALL subject should consist of:
a) Computer or laptop
b) smart phone
c) $L C D$
d) Internet
e) Loud speakers

To get some free softwares, you as a teacher can give some lists of website which provide those softwares freely for example www. filehippo.com, www. 4share.com, and so forth. It is hoped that the students are able to download what they need to support their learning materials

\section{3) Preparing Individual Final Project}

The goal of final project is to measure student's understanding about the technology materials that they have studied before. What the students have to do is to follow the given instructions in doing the project. In general, the project is asking the students to create products of learning which integrate it with the four English skills (Listening, Speaking, Reading and Writing). The products can vary such as book, application, online course, videos and so on. However, before they do their project, they should propose a project plan individually and get approval from their teacher. They just have two weeks to finish their project, soon after the fourtenth meeting, they can start to do their project. The criteria for grading the project are original idea, creativity and innovation, content, usefulness. The grade from this project is added to other grade forms such as class participation, assignment and present as the final grade for the TALL subject. All guidances, requirements and rules about this final project should be given to each student in a written form at the first meeting of the subject

4) Preparing Weekly Assignment

In this TALL subject, there are two assignments which should be done regularly by students. Firstly, doing consultation before workshop. This assignment is a obligation for groups (based on the given schedule) which are going to do workshop in laboratory/classroom. The should consultate at least once with their teacher before the day of their workshop. The objective of this consultation is to ensure that they have prepared all materials they need to give a workshop to their friends in laboratory. As a counselor/fasilitator, the teacher checks the topics or presentation slides whether it is suitable or not with the syllabus. In addition, the teacher gives advice, comment, suggestion or even correction if there is any mistake with their preparation and materials. The grade/score for this assignment is based on their preparation until their performance in giving workshop. There will be a questionaswer session among students, and practice session on computer/laptop during workshop.

Secondly, reporting ideas about the use of technology for their learning and teaching in the future. This is an individual assignment and should be submitted a day before the class begins. In the assignment, the students write a reporting paragraph about the technology that they have learned before. The paragraph should contain logical ideas on how to use it for their own learning and teaching English in the next time. The teacher gives feedback and mark on their work weekly. All information about this weekly assignment should be given at the first meeting with students.

\section{5) Grouping Students into Permanent Group}

The objective of forming the group here is to prepare the students with their weekly workshop. To determine the members of the group, the teacher can ask the students to select their group by themselves or the teacher him/herself by looking at their attendance list from $\mathrm{A}-\mathrm{Z}$ and divide them into some groups based on their initial names. However, the teacher is free to determine the system of choosing group member. It is suggested to make sure that the group members come from various compositions such as gender, ability, ethnic group and background. Finally, it is also recommended to form the group at the first meeting because their workshop are going to start in their second meeting.

Evaluation sheet is needed to be prepared by teacher because it will be used to record or to note the student's score on their assignments and final project and other important notes such as participation or egagement of students in class. The sheet contains about their names, their scores for each assignment and final project and their participation The information on this sheet is useful for teacher as additional data before giving final mark/score on this TALL subject.

\section{Step 2. Teaching Activities \\ 1) Workshop}

The main activity for teaching TALL subject is a workshop conducted by a appointed group of students. The steps for doing this are

\section{a) Pre-Workshop}

Class is firstly opened by a teacher to explain the goals of the teaching topic and then ask the group to do their workshop. Besides, in the pre workshop the teacher can also review the last assignment and giving some advice and 
suggestions for improvement in the future. The allocated time for this session is approximately 5-10 minutes

\section{b) Whilst Workshop}

The group members come to the front and introduce their name and the topic which is going to be presented and discussed in the workshop. In doing workshop, the presenter can choose two methods in delivering their workshop.

First of all, they can explain all material first, then going to practice session, or they give explain materials and practice directly at the same time. However, commonly students prefer to the first choice; explain first then practice.While the group explains the material, the teacher notes all things about their performance: contents, question and participation on his/her evaluation sheets. In addition, all audience are hoped to focus on what speaker's explanation because they have to write down the points which will be useful for their individual assignment.

Secondly, after following the group presentation, each student, supported by group member of workshop, opens their computer and or laptop to practice about what they have learned from the goup's explanation before or from worksheet provided by presenter. During the practice time, all members of group workshop walk around the laboratory to ensure that their classmates can understand and follow the instructions given to them. The teacher just watches and observes the class $A$ in order to the workshop runs well. Finally, allocated time for this presentation is about 20 minutes and practice session is around 60 minutes.

c) Post workshop

At the end of workshop, one of presenters instructs to stop working and ask to summarize what the materials that have been discussed. Then, the class will be handled by teacher. Before the class is closed, the teacher gives some feedback on the workshop and remind them about the weekly assignment and next topic. Time allocation for this post activity is around 5-10 minutes.

\section{2) Teacher's Roles}

In this TALL subject, the roles of teacher are firstly, as a provider. Before class begins, the teacher provides all guidances including list of materials and learning sources which are going to discussed by students later on. Secondly, as a counselor due to teacher gives consultation to members of group students before they perform their workshop in laboratory or classroom. Thirdly, as a facilitator, the teacher facilitates all students to give involved actively in classroom, including if the have difficult question, the teacher also tries to answer that questions. Fourthly, as a motivator, the teacher always gives support and motivation to students to do all assignments perfectly and can work together in a team.

\section{3) Student's Roles}

Since this TALL class emphasizes on student centered learning, the roles of students seems significant here. They are all expected to be an active student for each activity. For example, in group workshop, all members should contribute to their group's achievement to get better result on their work performance starting from preparation step to workshop. The roles could be searcher, collector, presenter, moderator, designer, and creator for their workshop. Team's achievement depends on their member's contribution.

C. Step 3. Post Teaching Activiies

\section{1) Grading}

After the class finish, all components of final score for TALL subject such assignment score, class participation score, project score, present percentage are counted to gether to see final mark of the subject for each student. Before, the official marks are posted on Academic Website, the teacher published it in class. The students come to see their final mark and then they are free to make a complaint if any problems with their mark.

\section{2) Evaluation}

The last step for teaching TALL is evaluation. This evaluation covers about teaching material and source, teaching activity, assignment/project, grading system and feedback. This evaluation is intended for improvement of teaching the subject in future.

\section{REFLECTION ON TEACHING TALL}

Teaching technology as assisted language learning gives some reflections for teachers to consider it as one of the ways to help learners in language learning

A. Teachers of English should be update person with the development of technolgy

B. Provide students with some information of technology and source and let them explore it

C. Teachers of English should be update person with the development of technolgy

\section{CONCLUSION AND RECOMMENDATION}

Teaching technology as assisted language learning (TALL) subject is an answer for student's demand to support their language learning and teaching in the future. By providing students with useful technology and integrate it into English language skills, it is hoped that they are good at both English and technology

It is highly recommended for teachers or schools/universities to provide their students with skill in technoloy to support their language proficiency. Standard laboratory, internet access and its speed are needed by students to promote their potential in exploring advanced technology as tools to enhance their skills in English

\section{Acknowledgment}

The authors would like to express higly deepest appreciation for the dean of Faculty of Teacher Training and Education, Bengkulu University who has sponsored us to publish this article.

\section{References}

[1] Prakash, Lakshmi Sunil, and Dinesh Kumar Saini. "Instructional design technology in higher education system: role and impact on developing creative learning environments." Handbook of Research on Creative Problem-Solving Skill Development in Higher Education. IGI Global, 2017. 378-406 
[2] Berta, Riccardo, et al. "A tangible serious game approach to science, technology, engineering, and mathematics (STEM) education." Handbook of Digital Games and Entertainment Technologies. Springer Singapore, 2017. 571-592.

[3] Kim, Daesang, Daniel Ruecker, and Dong-Joong Kim. "Mobile assisted language learning experiences." International Journal of Mobile and Blended Learning (IJMBL) 9.1 2017: 49-66

[4] Nielson, Katharine B. "Mobile-assisted language learning: researchbased best practices for maximizing learner success." Blended Learning: Concepts, Methodologies, Tools, and Applications. IGI Global, 2017. 818-842.

[5] Palomo-Duarte, Manuel, et al. "Assessing foreign language learning through mobile game-based learning environments." Blended Learning: Concepts, Methodologies, Tools, and Applications. IGI Global, 2017. 964-981.

[6] Hsu, Liwei. "Examining EFL teachers' technological pedagogical content knowledge and the adoption of mobile-assisted language learning: a partial least square approach." 2017.

[7] Lee, Lina. "Learners' perceptions of the effectiveness of blogging for L2 writing in fully online language courses." International Journal of Computer-Assisted Language Learning and Teaching (IJCALLT) 7.1 (2017): 19-33.

[8] Chauhan, Sumedha. "A meta-analysis of the impact of technology on learning effectiveness of elementary students." Computers \& Education 105 (2017): 14-30.

[9] Alberth. "Technology-enhanced teaching: a revolutionary approach to teaching English as a foreign language." TEFLIN Journal.Volume 24, Number 1.(2013): 1-13

[10] Sithira Vadivel, Insu Song, Abhishek Singh Bhati. "Improving teaching and learning in Southeast Asian secondary schools with the use of culturally motivated web and mobile technology." Information and science and Application .2017.pp 652-659

[11] Jones, Lewis CR. An investigation into the knowledge and skill requirements for effective teaching of technology in English secondary schools. Diss. Loughborough University, 2016. 